\title{
Case Report: Leprosy and Psoriasis: A Rare Coexistence
}

\author{
Umar A. Sheikh ${ }^{1} \dagger$ and Carlotta Hill ${ }^{2 *}$ \\ ${ }^{1}$ Saint Louis University School of Medicine, St. Louis, Missouri; ${ }^{2}$ Department of Dermatology, School of Medicine, University of Illinois,
} Chicago, Illinois

\begin{abstract}
Leprosy presents with erythematous or pigmented patches, plaques, and nodules with loss of sensation and nerve thickening. Psoriasis presents as sharply demarcated erythematous plaques with overlying silvery scales. The controversial relationship between both has existed since biblical times when psoriasis was considered to be a form of leprosy. Records of leprosy patients have depicted a rarity of the coexistence of psoriasis, leading to a hypothesis that both rarely develop in the same patient. We report a rare coexistence of both diseases.
\end{abstract}

\section{INTRODUCTION}

Leprosy is a chronic granulomatous disease caused by Mycobacterium leprae which presents with erythematous or pigmented patches, plaques, and nodules with varying loss of sensation and nerve thickening. Psoriasis is an inflammatory dermatosis characterized by increased epidermal proliferation that classically presents as sharply demarcated erythematous papules and plaques with overlying silvery scales. The controversial relationship between leprosy and psoriasis has existed since biblical times when psoriasis was considered to be a form of leprosy. ${ }^{1}$ Records of leprosy patients have depicted a rarity of the coexistence of psoriasis, leading to a hypothesis that leprosy and psoriasis rarely develop in the same patient and that both diseases may be protective against development of the other. ${ }^{2}$ We report a rare case of coexistence of leprosy and psoriasis.

\section{CASE}

A 63-year-old man of Norwegian ancestry presented with two distinct rashes: erythematous plaques with overlying silvery scale scattered across his trunk and extremities and erythematous hyperpigmented annular to serpiginous patches with raised borders widely distributed across his back (Figures 1-3).

The patient had a known diagnosis of psoriasis for over 10 years that had been treated with light therapy and cyclosporine. The patient developed numbness in his left leg which started spreading to his hands and face and was diagnosed with small nerve neuropathy. Travel history was notable for vacations to Mexico for six consecutive years during this period. The patient denied contact with armadillos.

Biopsy of the left superficial peroneal nerve was indicative of lepromatous leprosy, and skin biopsy from the back demonstrated noncaseating granulomas, indicative of borderline tuberculoid leprosy (Figures 4 and 5). Fite stains of both were positive. Skin biopsy of the trunk demonstrated psoriasiform dermatitis with negative Fite stains (Figure 6). The patient was started on minocycline, rifampin, and dapsone for his leprosy, oral prednisone for his neuritis, and light therapy for his psoriasis.

\footnotetext{
* Address correspondence to Carlotta Hill, Department of Dermatology, University of Illinois, Chicago 1801 West, Taylor St., Chicago, IL 60612. E-mail: chhill@uic.edu

$\dagger$ These authors contributed equally to this work.
}

\section{DISCUSSION}

Coexistence of psoriasis and leprosy is rare in the published literature. A survey of 145,661 cases of leprosy found only 20 individuals with psoriasis. ${ }^{3}$ The exact cause of this association is unclear but may be influenced by genetics, immunology, and the role of neuropeptides. One proposed hypothesis is that resisting leprosy may have been the evolutionary advantage that favored the expansion of psoriasis-associated genotypes. ${ }^{4}$ HLA-DR2 and HLA-DQW1 have been associated with leprosy, whereas HLA-B13 and BLA-B17 have been associated with psoriasis. ${ }^{5}$

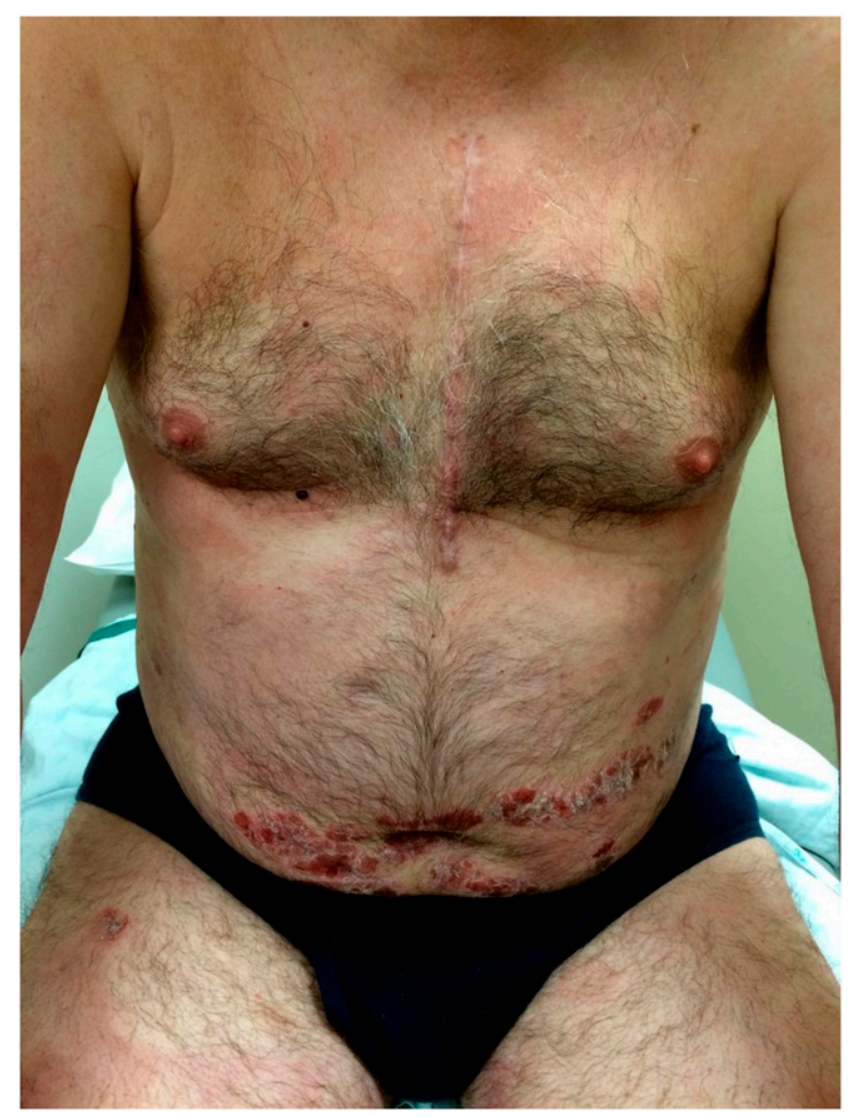

FIGURE 1. Erythematous plaques with overlying silvery scales on the abdomen, elbows, and knees bilaterally. This figure appears in color at www.ajtmh.org. 


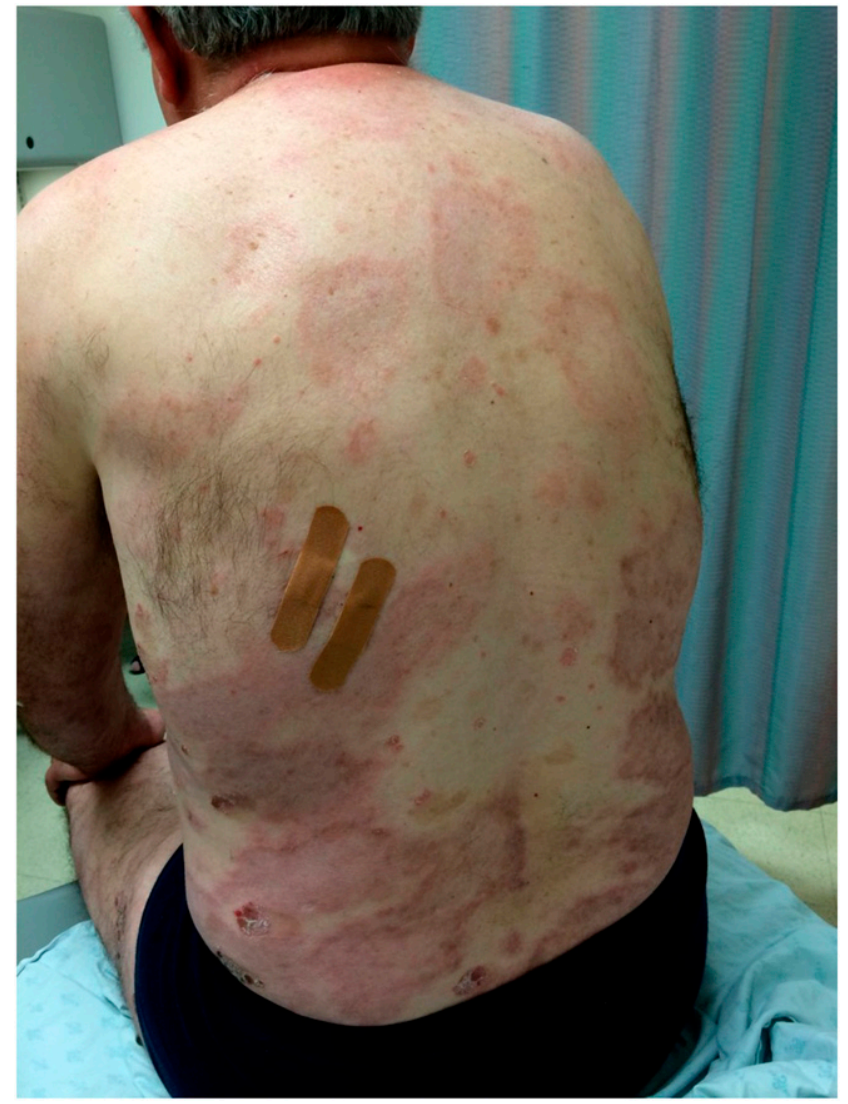

FIGURE 2. Annular patches with scales can be seen on the upper and lower back. This figure appears in color at www.ajtmh.org.

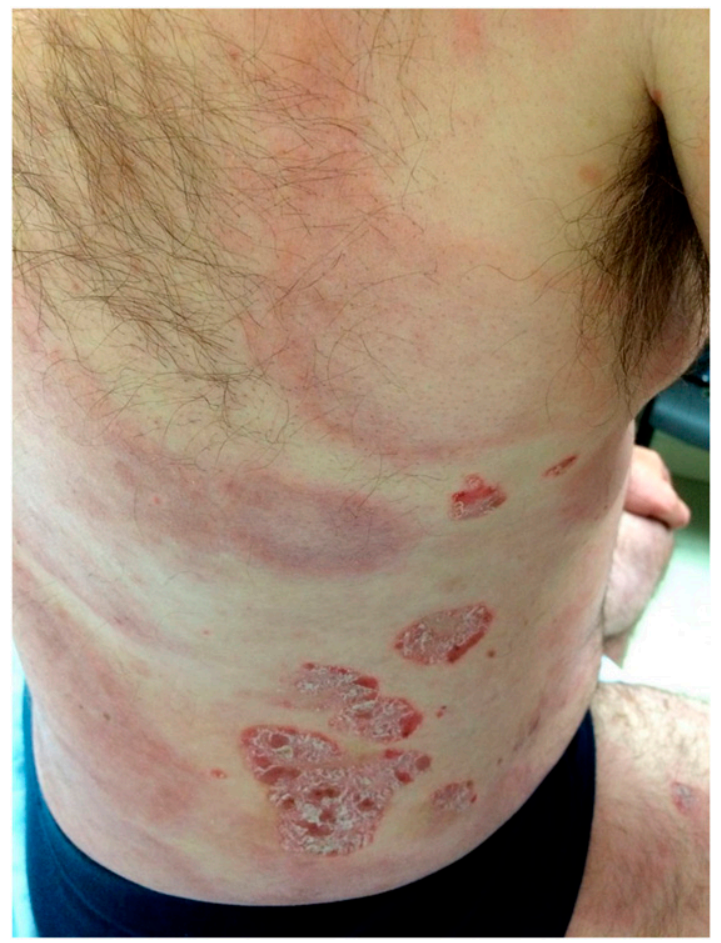

Figure 3. Closer view of both type of lesions: erythematous plaques with overlying silvery scales and large annular patches. This figure appears in color at www.ajtmh.org.

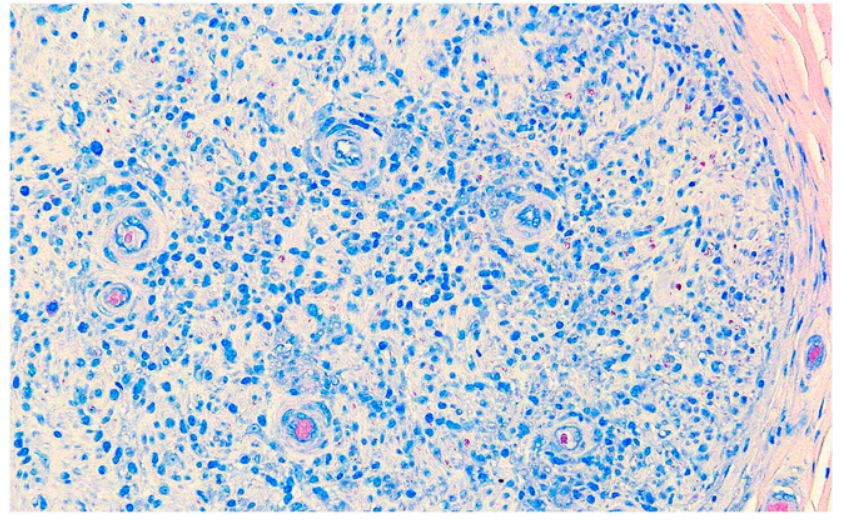

FIGURE 4. High-power Fite stain of the left peroneal nerve revealing a large number of acid-fast bacilli within the histiocytes and Schwann cells in the nerve fascicles. This figure appears in color at www.ajtmh.org.

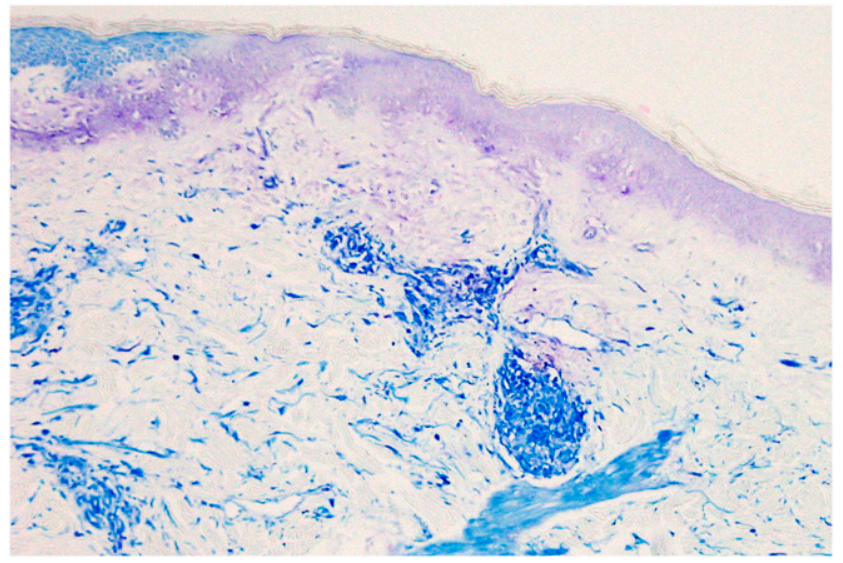

FIGURE 5. Fite stain of the biopsy of the hyperpigmented patch on the patient's back revealed a small number of acid-fast bacilli. This figure appears in color at www.ajtmh.org.

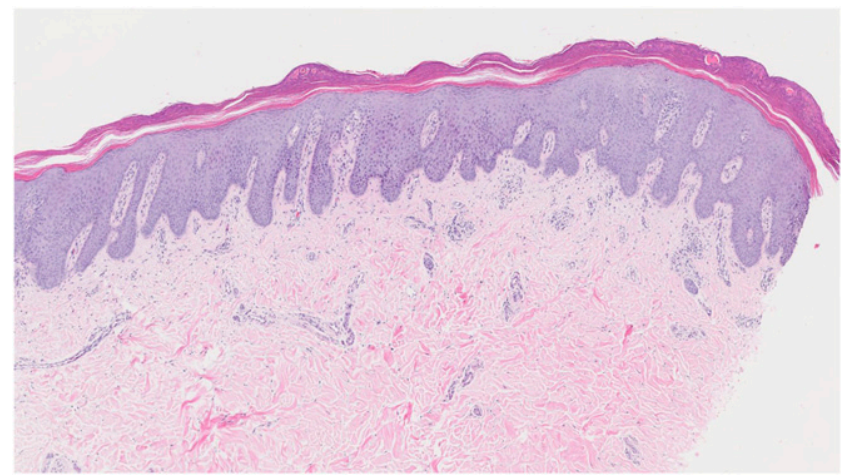

Figure 6. Punch biopsy from a psoriatic lesion on the abdomen consistent with psoriasis. This figure appears in color at www.ajtmh.org. 
Lepromatous leprosy is characterized by a predominant Type 2 helper T-cell (Th2) immune response and failure to build granulomas in lesions, whereas tuberculoid leprosy is characterized by a Th1 immune response and granulomatous inflammation. Psoriasis is characterized by a genetic predisposition to strong Th1 immune polarization that may evolutionarily keep $M$. leprae under control, by conversion to the tuberculoid form of the disease which the body is able to spontaneously clear, and favor survival during a leprosy epidemic. This has led to the hypothesis that psoriasis may protect against the clinical progression of leprosy and that leprosy may have been historically contained because of the increased prevalence of psoriasis. ${ }^{4}$

Nerve involvement in leprosy leads to destruction of cutaneous nerve fibers and absence of neuropeptides such as substance $\mathrm{P}$, which may play a functional role in psoriatic proliferation. Damage to sensory nerves has been reported to clear psoriatic lesions, leading to the hypothesis that it may be the leprosy-associated neuropathy that results in inhibiting the psoriatic disease process. ${ }^{5}$

The patient is of Norwegian ancestry, which was the last European country with the highest concentration of endemic leprosy. ${ }^{6}$ Today, Norway is one of the countries with the highest prevalence of psoriasis. ${ }^{7}$ Our case report documents a rare presentation of the coexistence of leprosy and psoriasis in a single patient.
Received August 30, 2019. Accepted for publication March 1, 2020.

Published online April 27, 2020.

Authors' addresses: Umar A. Sheikh, Saint Louis University School of Medicine, St. Louis, MO, E-mail: umar.sheikh@health.slu.edu. Carlotta Hill, Department of Dermatology, University of Illinois, Chicago, School of Medicine, Chicago, IL, E-mail: chhill@uic.edu.

\section{REFERENCES}

1. Dogra S, Kaur I, Kumar B, 2003. Leprosy and psoriasis: an enigmatic relationship. Int $J$ Lepr 71: 341-344.

2. Wahba A, Dorfman M, Sheskin J, 1980. Psoriasis and other common dermatoses in leprosy. Int J Dermatol 19: 93-95.

3. Kumar B, Raychaudhuri SP, Vossough S, Farber EM, 1992. The rare coexistence of leprosy and psoriasis. Int $J$ Dermatol 31: 551-554.

4. Bassukas ID, Gaitanis G, Hundeiker M, 2012. Leprosy and the natural selection for psoriasis. Med Hypotheses 78: 183-190.

5. Pai W, Kikkeri NN, Athanikar SB, Rao R, 2013. Psoriasis and leprosy: a mystifying coexistence. Cutis 92: E3-E4.

6. Schexnyder E, 2019. Hansen's Disease. New Orleans Historical. Carville, LA: National Hansen's Disease Museum. Available at: https://neworleanshistorical.org/items/show/634. Accessed June 3, 2019.

7. Griffiths CEM, van der Walt JM, Ashcroft DM, Flohr C, Naldi L, Nijsten T, Augustin M, 2017. The global state of psoriasis disease epidemiology: a workshop report. $\mathrm{Br} J$ Dermatol 177: e4-e7. 